\title{
Chylopericardium associated with constrictive pericarditis assessed by multimodality imaging
}

Emmanuel Androulakis ${ }^{1}$, Konstantinos Bratis ${ }^{2}$, TP Chua ${ }^{2}$, and Venkatachalam Chandrasekaran ${ }^{2}$

${ }^{1}$ Royal Brompton and Harefield NHS Foundation Trust

${ }^{2}$ St George's University Hospital

January 13, 2021

\begin{abstract}
Abstract An 80-year-old male patient developed exertional dyspnea and bilateral peripheral oedema. Investigations including an echocardiogram, cardiac computed tomography and cardiac magnetic resonance suggested calcific pericardial thickening encapsulating the heart with associated constriction. This is an interesting case as constriction was associated with a large chylopericardium of unknown cause
\end{abstract}

\section{Hosted file}

Case report CCR.pdf available at https://authorea.com/users/389296/articles/503919chylopericardium-associated-with-constrictive-pericarditis-assessed-by-multimodalityimaging

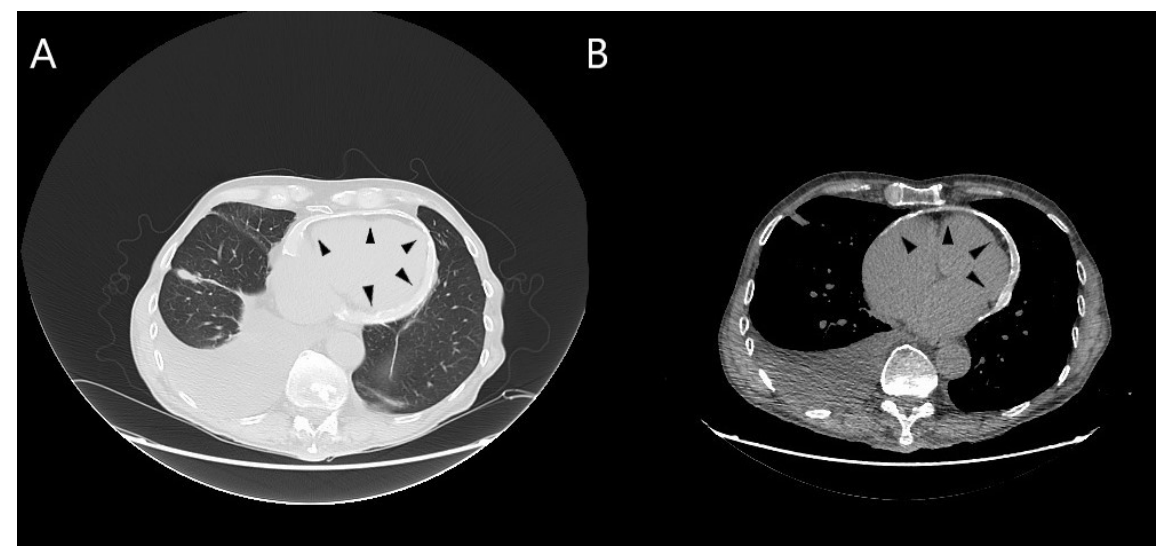




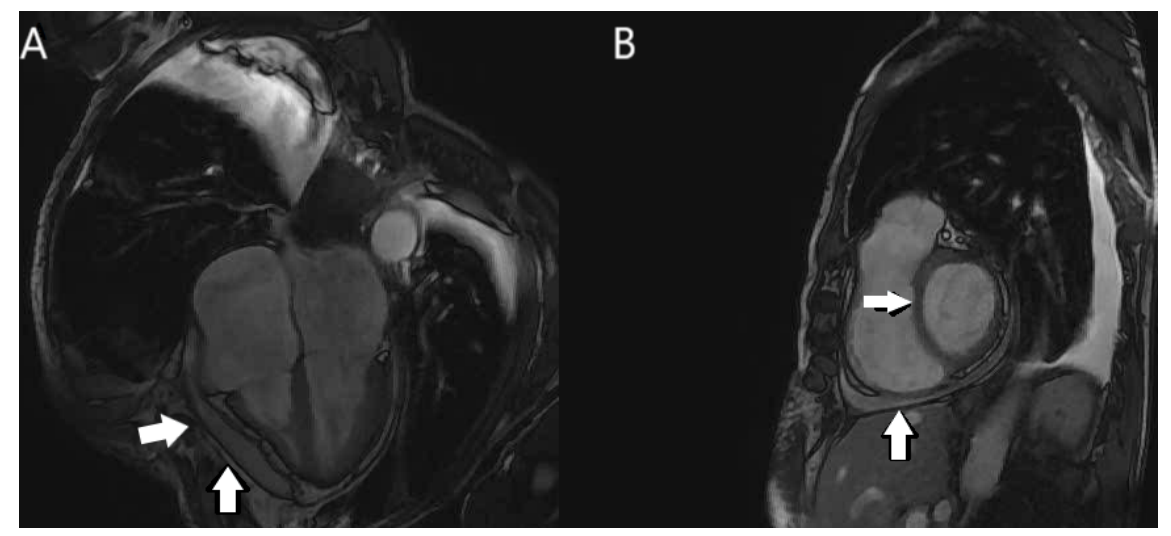

